\title{
Effect of kind of exercise training on gene expression of $\beta 3-A R s$ and A2ARs receptors of brown adipose tissue in obese male rats
}

\author{
Shohre Sharifian ${ }^{1}$, Ramin Shabani ${ }^{2}$, Mohammad Ali Azarbayjani $^{3}$, Alireza Elmieh ${ }^{4}$ \\ ${ }^{1}$ PhD Candidate of Exercise Physiology, Department of Physical Education and Sport Sciences, Faculty of Humanities, \\ Rasht Branch, Islamic Azad University, Rasht, Iran \\ ${ }^{2}$ Associate Professor, Department of Physical Education and Sport Sciences, Faculty of Humanities, Rasht Branch, \\ Islamic Azad University, Rasht, Iran \\ ${ }^{3}$ Professor, Department of Physical Education and Sport Sciences, Faculty of Sport Sciences, Central Tehran Branch, \\ Islamic Azad University, Tehran, Iran \\ ${ }^{4}$ Assistant Professor, Department of Physical Education and Sport Sciences, Faculty of Humanities, Rasht Branch, \\ Islamic Azad University, Rasht, Iran
}

\begin{abstract}
Background: The aim of present study was to investigate the effect of a period of endurance training and high intensity intermittent training on gene expression of $\beta 3$-Adrenergic ( $\beta 3$-ARs) and A2A (A2ARs) receptors of brown adipose tissue in obese male Wistar rats.

Materials and methods: In an experimental trial, 15 male Wistar rats were randomly divided into three groups, including endurance training group $(n=5)$, high intensity intermittent training group $(n=5)$ and control group $(\mathrm{n}=5)$. The training protocol included 5 sessions per week for 12 weeks. The gene expression of $\beta 3$-Adrenergic and A2ARs were examined by qRT- PCR. The Kruskal-Wallis was used to analysis the data and significant level was set at $\mathrm{p}<0.05$.

Results: There was no significant difference in gene expression of $\beta 3$-ARs among groups $(p=0.097)$, but endurance training caused the significant increase in gene expression of A2ARs compared to control group $(p=0.030)$. The weight did not show any significant difference among groups $(p>0.05)$.

Conclusion: Our results showed that endurance training induced significant enhance in gene expression of A2ARs of brown adipose tissue. This result can be due to suitable intensity and during of this training on A2ARs. According to results of this study, it is concluded that endurance training prevents high fat diet induced obesity.

Keywords: Brown adipose tissue, Endurance training, High intensity intermittent training, High fat diet.

Cited as: Sharifian S, Shabani R, Azarbayjani M A, Elmieh A. Effect of kind of exercise training on gene expression of $\beta 3$-ARs and A2ARs receptors of brown adipose tissue in obese male rats. Medical Science Journal of Islamic Azad University, Tehran Medical Branch 2019; 29(1): 27-36.
\end{abstract}

Correspondence to: Ramin Shabani

Tel: +989112324796

E-mail: shabani_msn@yahoo.com

ORCID ID: 0000-0002-2681-3814

Received: 26 May 2018; Accepted: 26 Aug 2018 
مجله علوم يزشكى دانشگًاه آزاد اسلامى

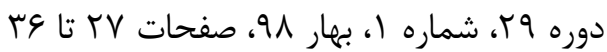

Original

Article

\section{تاثير نوع تمرين بر بيان زن گَيرنده B3-ARs و A2ARs در بافت جربى قهوهاى رتهاى نر צاق}

\section{شهره شريفيان' ، رامين شعبانى '، محمدعلى آذربايجانى '، عليرضا علميه}

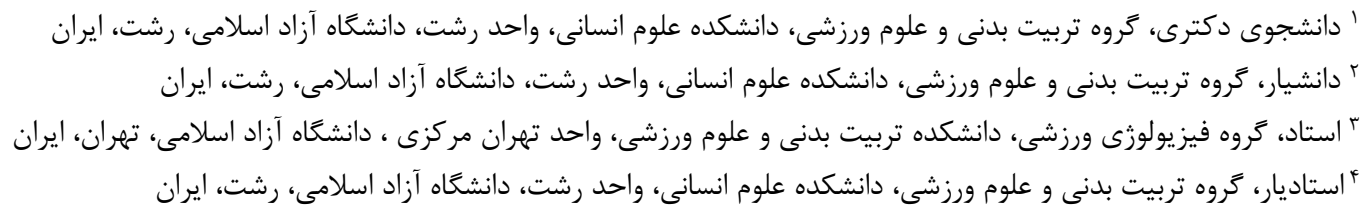

سابقه و هدف: هدف /ز تحقيق حاضر، بررسى تاثير يك دوره تمرين /ستقامتى و تمرين تناوبى با شدت بالا بر بيان زن كيرندهاى بتا

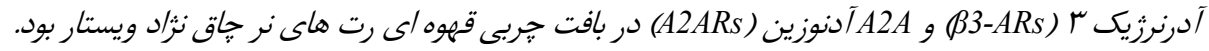

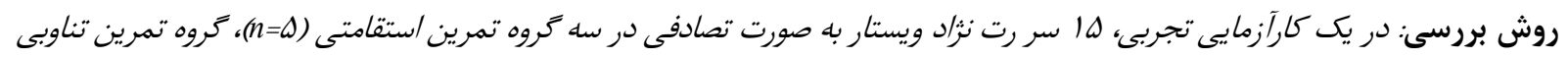

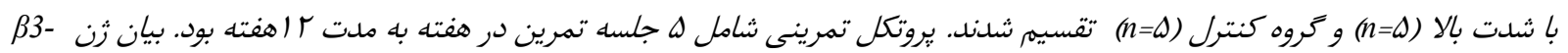

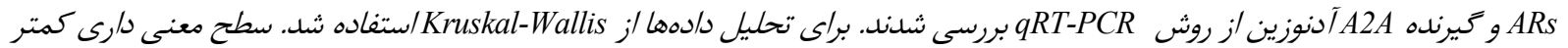

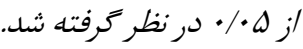

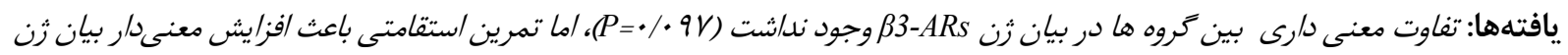

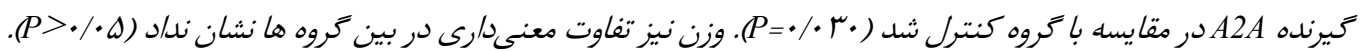

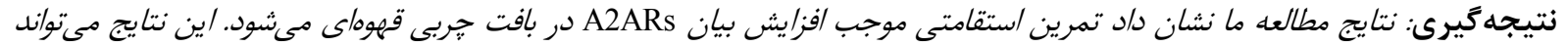

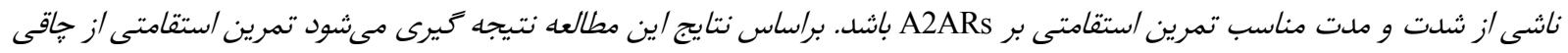

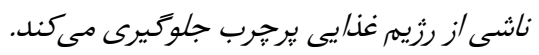

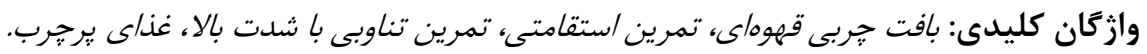

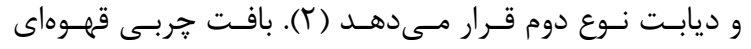
مقدمه نوع ترموزنيك بافت جربـ (Brown adipose tissue :BAT) است و حاوى تعداد زيادى ميتوكندرى و ذخاير فـراوان ليِيــاسيد

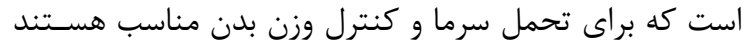

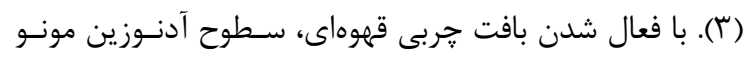

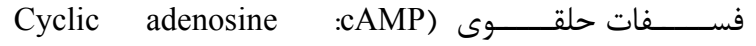
(monophosphate به سرعت افزايش يافته، منجربه ليـوليز و و (C)

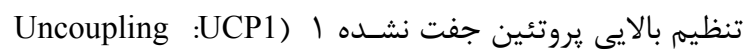
(Protein 1
رزيم غذايى نامناسب و عدم فعاليت بدنى از مهمتـرين عوامـل

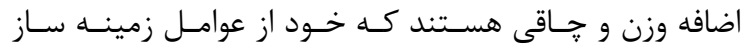

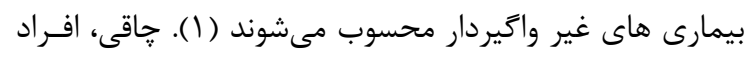
را در معرض بيمارى هاى شريان كرونرى، يرفشار خونى، سكتئه

آدرس نويسنده مسئول: رشت، دانشكاه آزاد اسلامى، كروه تربيت بــنى و علـوم ورزشسى، دكتـر رامسين شعبانى (email: shabani_msn@yahoo.com) ORCID ID: 0000-0002-2681-3814 تاريخ دريافت مقاله: تاريخ بذيرش مقاله: 9V/9/4 
كاهش در كرماز ايى وابسته به BAT شد، درحالى كه درمان بـا

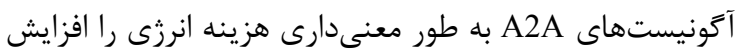

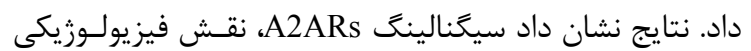
غير منتظرهاى در فعال شدن سمياتيكى بافت خربسى قهـومائ

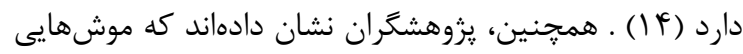

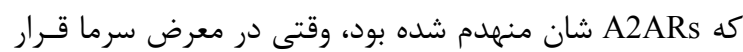

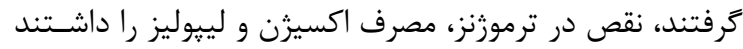

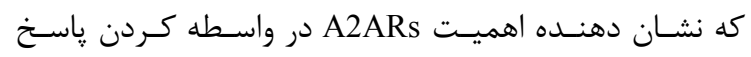

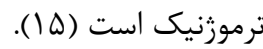

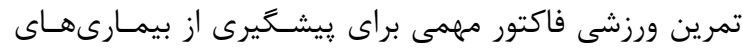

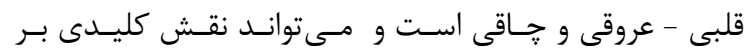
متابوليسم بافت جربى قهوهاى اعمال كند (1) (1). توليد آدنوزين

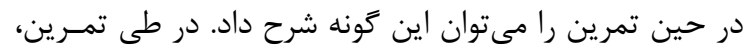

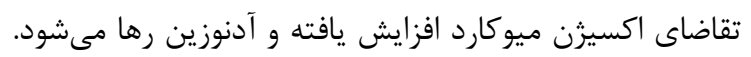

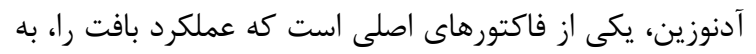

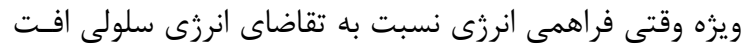

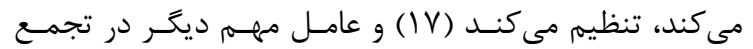

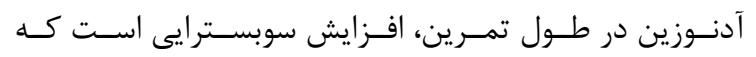

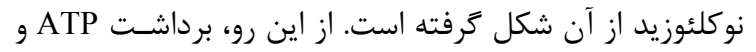

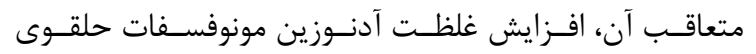

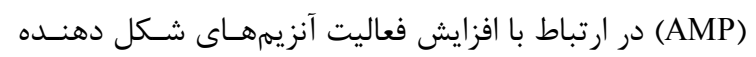

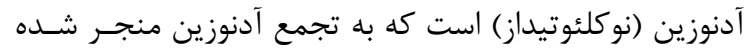

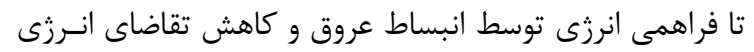

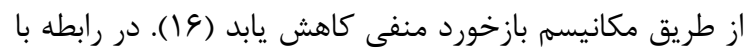

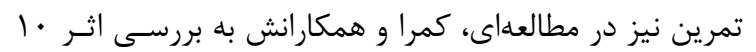

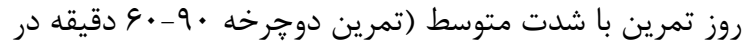

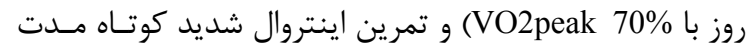
(شامل 9 تكرار ه دقيقـهاى در 90\%

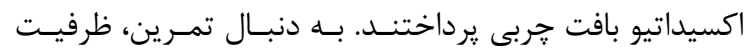

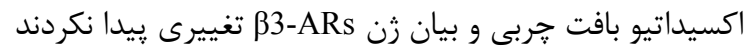

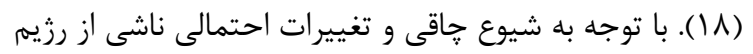

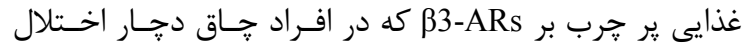

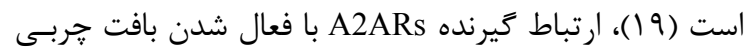

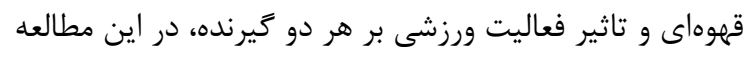

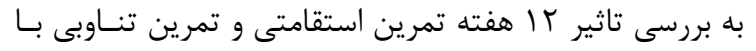

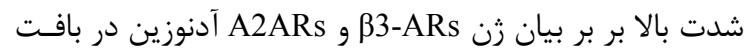

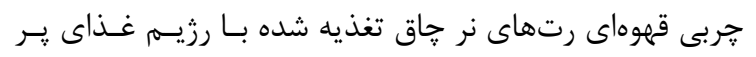

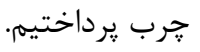

بافت جربى قهوهاى فعال، مقــدار قابـل تـوجهى از سوبسـتراى

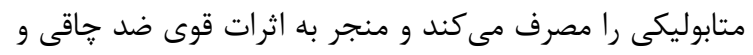

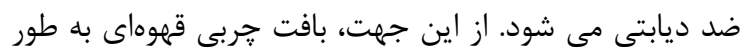

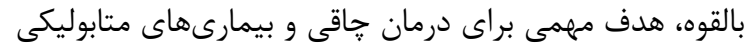

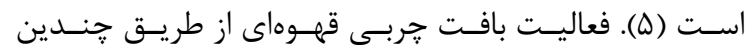

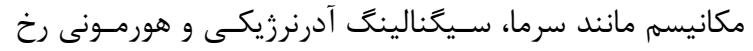

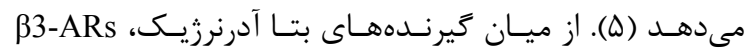
(Beta-3 adrenergic receptors)

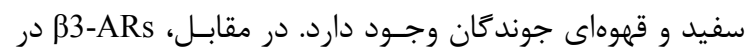

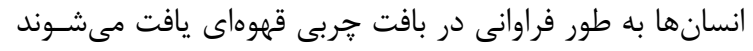

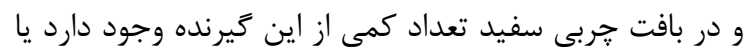

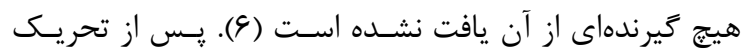

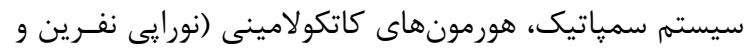

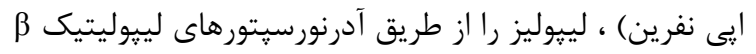

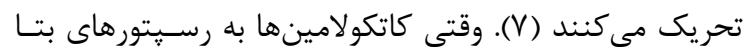
آدرنرزيك متصل مىشوند انتقال دهندههاى غشايى نيز فعـال

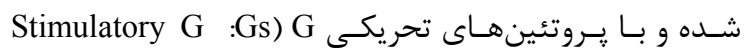

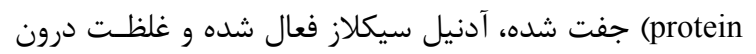
سلولى cAMP افزايش مى يابد و به نوبه خود باعث فعال شدن

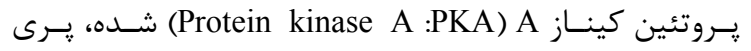
ليبين و ليهياز حساس به هورمون (HSL

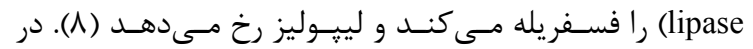

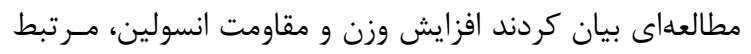

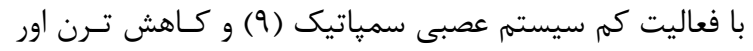
(turnover)

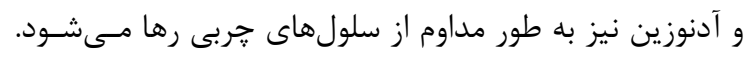

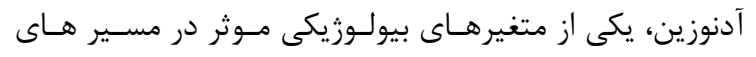

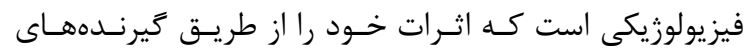

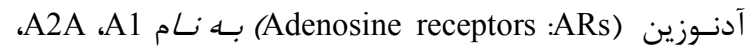
تو A2B ور بافتهاى مختلف انجام مى دهد. رهايى آدنوزين

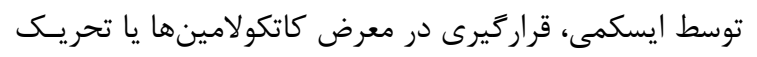

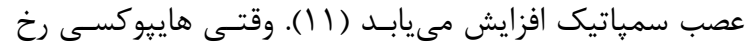

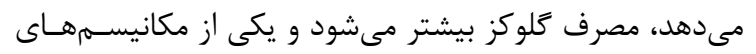

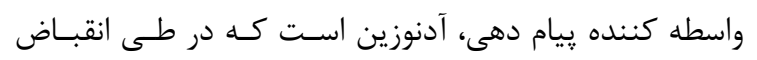

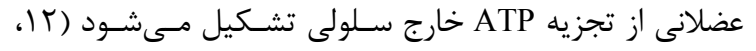

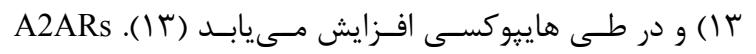

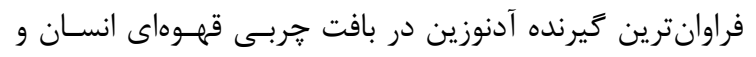

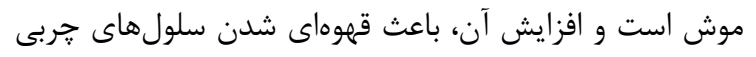

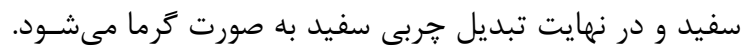

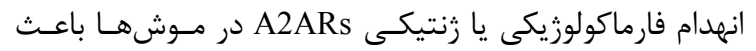


يروتكل تمرين استقامتى به صورت ييشرونده بود و بـا سـرعت

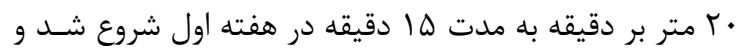

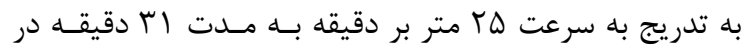

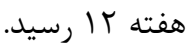

يروتكل تمرين تناوبى با شدت بالا با سرعت اس متر بر دقيقـهـ

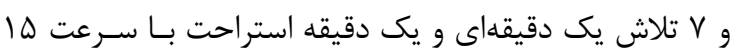
متر بر دقيقه در هفته اول شروع شد و به تدريج به سرعت هله متر بر دقيقه و • ا تلاش يك دقيقهاى و يك دقيقه اسـتراحت با سرعت هr متر بر دقيقه در هفته r ا رسيد.

\section{سنجش و بررسى بافتى}

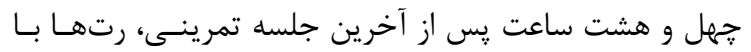
تزريق درونصفاقى تركيبى از كتامين (V) (V) ) و زايلازيسن

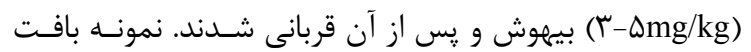
جربى قهوه اي از اينترا اسكايولار بين كتفـى گرفتـه شـد و وبـا

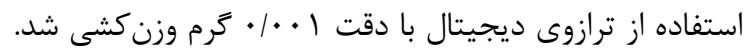

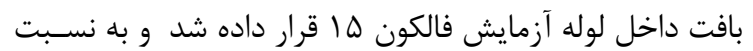

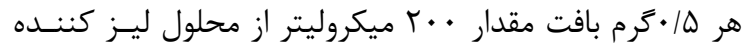

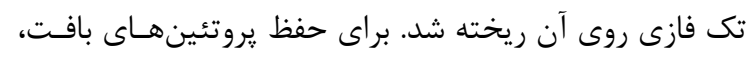

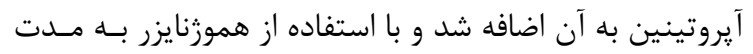
ينج دقيقه با سرعت . . ㅅ دور در دقيقه بافت همـوزن شـد.

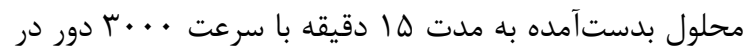

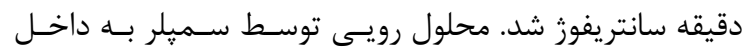
ميكروتيوب منتقل شد، جهت ارزيـابى متغيرهـاى مـورد نظـر

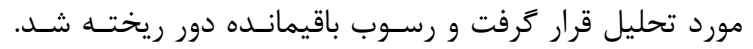

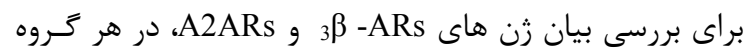
بررسى بافتها با تكنيك Real Time PCR استفاده شد. ابتـدا

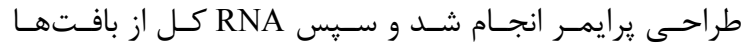

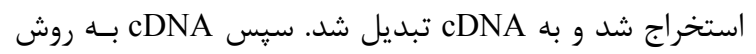
تكثير شد و از نظر بيان زن هاى ذكر شده مورد بررسى

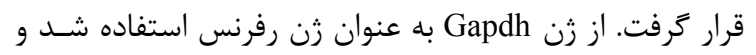

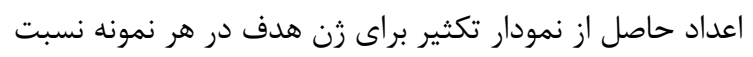

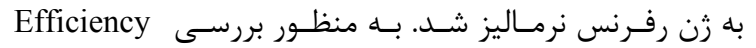

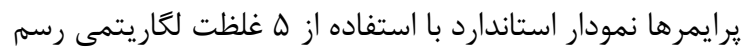

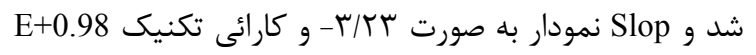
به دست آمد. در اين مطالعه نتايج با استفاده از فرمول فافـل و ودورات

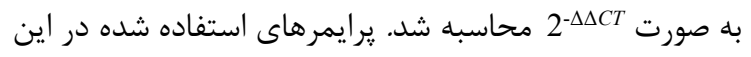

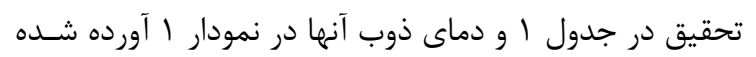

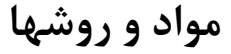

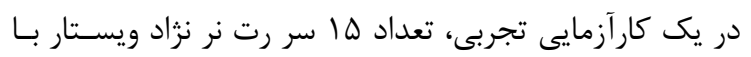

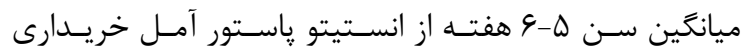

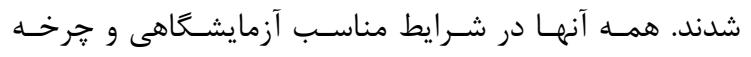

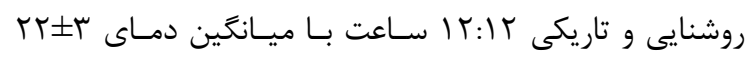

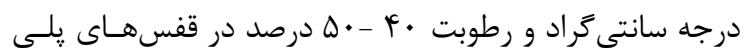

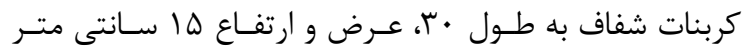

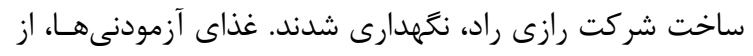

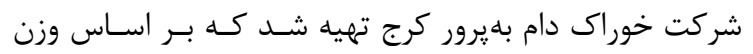

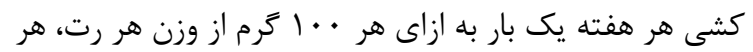

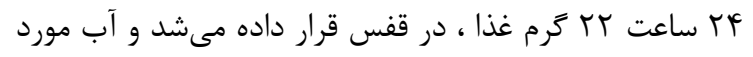

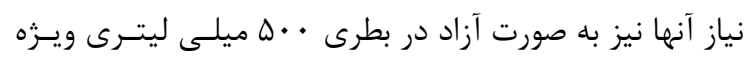

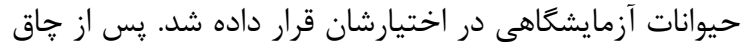

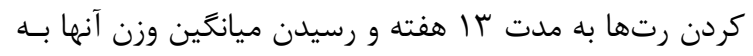

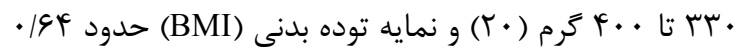

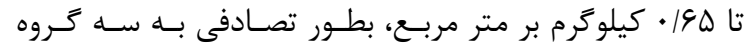

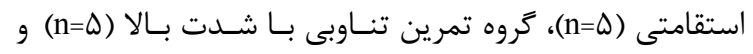

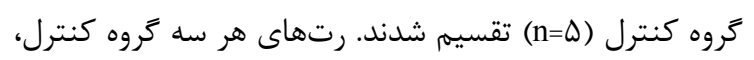

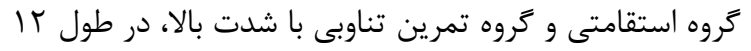

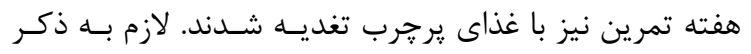

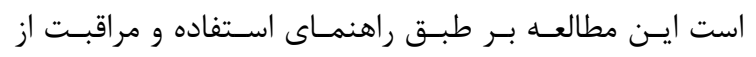

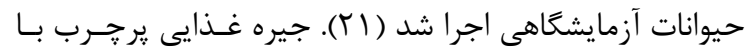

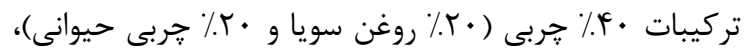

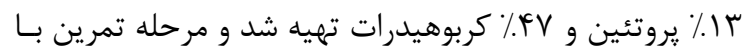

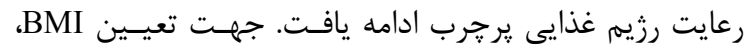
وزن و طول بدن (فاصله بينى تا مقعد يا همان طول بينسى تـا

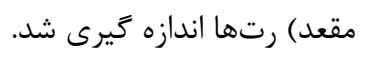

\section{يروتكل تمرين استقامتى و تمرين تناوبى با شدت بالا}

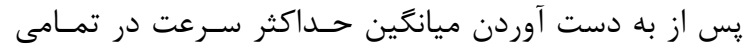

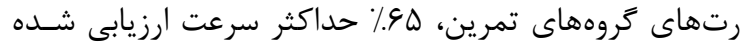

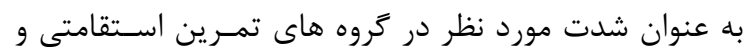

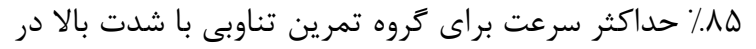

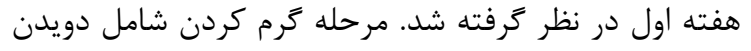

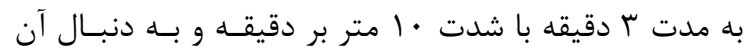

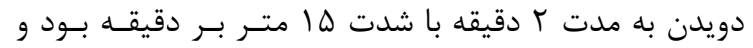

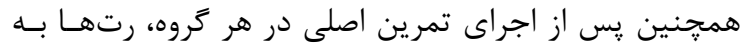

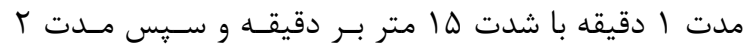

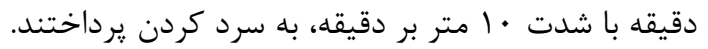




\begin{tabular}{|c|c|c|}
\hline \multicolumn{3}{|c|}{ لدول ا. اسامى، توالى و دماى ذوب برايمرهاى استفاده شده } \\
\hline ساى ذوب (درجه & توالى يرايمر & 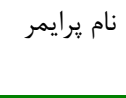 \\
\hline$\Lambda \cdot|\Lambda|$ & $\begin{array}{l}\text { F: 5' GAACACGAGCAAGAGGGA 3' } \\
\text { R: 5' GAGACACTTCACAGGGCAG 3', }\end{array}$ & Adora $2 b$ \\
\hline$\wedge / / \mathrm{V}$ & $\begin{array}{l}\text { F: 5' CAGAACTCACCGCTCAACAG 3' } \\
\text { R: 5' CATCCCACCCTACACCTCG 3' }\end{array}$ & Adrb3 \\
\hline $11 / 4$ & F: 5' AAGTTCAACGGCACAGTCAAGG 3' & Gapdh \\
\hline & R: 5' CATACTCAGCACCAGCATCACC 3' & \\
\hline
\end{tabular}

جدول ז. آزمون Kruskal-Wallis براى مقايسه بيان ثن B3-ARs و در سه كروه كنترل ، كروه تمرين استقامتى و كروه تمرين

\begin{tabular}{|c|c|c|c|c|c|}
\hline \multirow[b]{2}{*}{$\mathrm{P}$} & \multirow[b]{2}{*}{$\mathrm{F}$} & & \multicolumn{3}{|c|}{ كاوبى با شدت بالا (انحراف استاندارد 土 ميانكين) } \\
\hline & & انحراف معيار \ ميانكين & 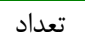 & 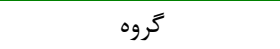 & متغير \\
\hline \multirow{3}{*}{$\cdot / \cdot \uparrow \Lambda$} & \multirow{3}{*}{$F / q 1 \Delta$} & $\cdot / \cdots \wedge \Lambda \pm \cdot / \cdots \varphi \vee$ & Q & 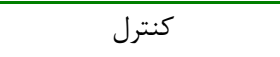 & A2Ars/Gapdh Ratio \\
\hline & & $\cdot|r| r \Delta| \pm \cdot /| \Lambda \mid \Delta V$ & $\Delta$ & تمرين استقامتى & \\
\hline & & $.1 \cdot v V \& V \pm .1 .4919$ & $\Delta$ & تمرين تناوبى با شدت بالا & \\
\hline \multirow{3}{*}{$.1 .9 \mathrm{~V}$} & \multirow{3}{*}{$r / \Lambda \Delta \Delta$} & $. / \cdot r \cdot r t \pm \cdot 1 \cdot r \cdot r t$ & $\Delta$ & 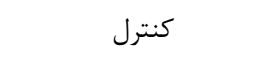 & $\beta 3$-ARs/Gapdh Ratio \\
\hline & & $r / \Delta \varphi \cdot \Delta r \pm r / q V F V$. & $\Delta$ & تمرين استقامتى & \\
\hline & & $T / F T \cdot V r \pm 1 / T A V A r$ & $\Delta$ & تمرين تناوبى با شدت بالا & \\
\hline
\end{tabular}
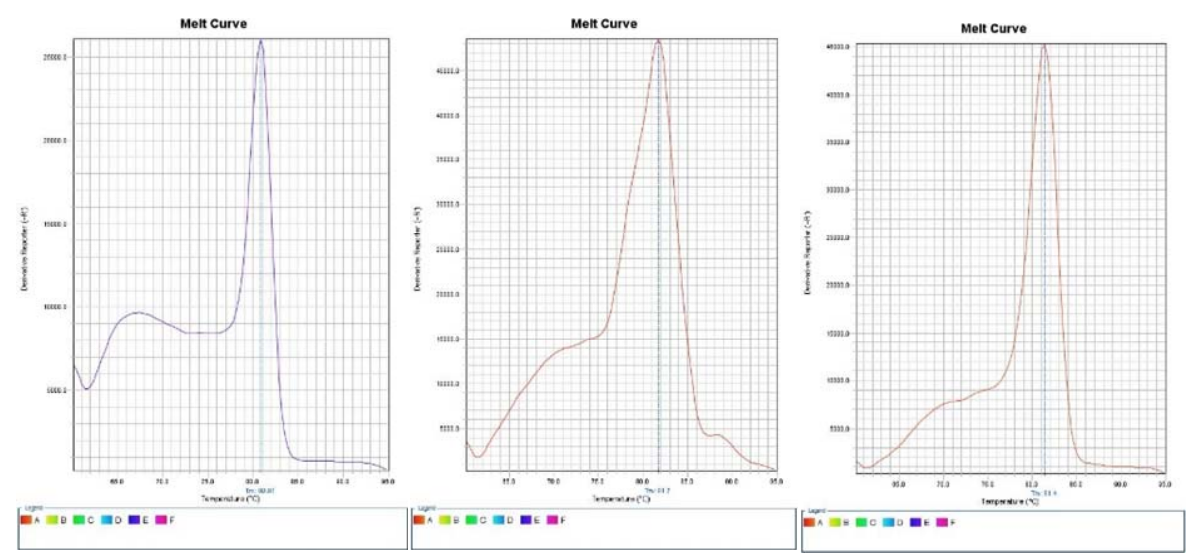

نمودار ا. دماى ذوب يرايمرهاى استفاده شده در اين تحقيق به ترتيب از سمت حٍِ مربوط به زن A2A،A3b،GapdhT،

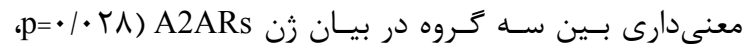

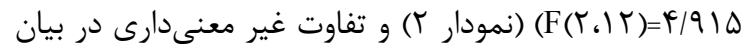

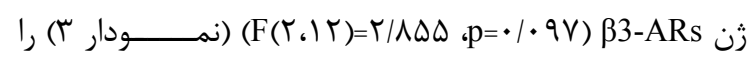

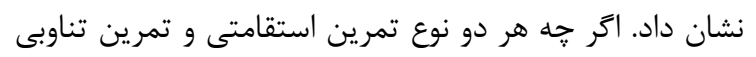

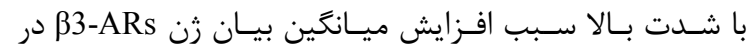

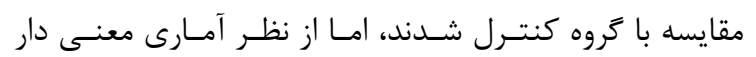

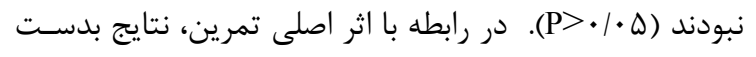

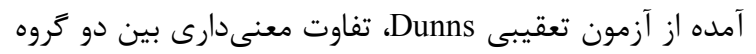

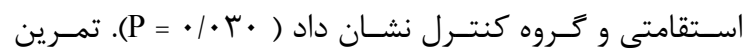

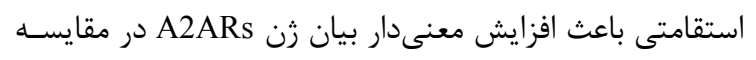

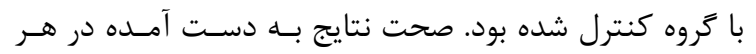

روش آمارى

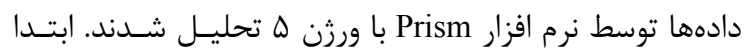

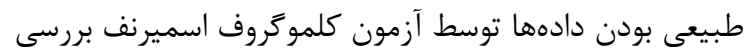

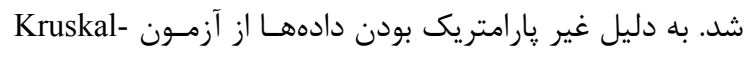

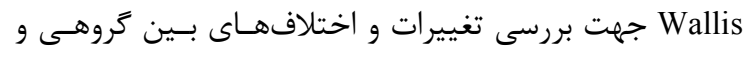

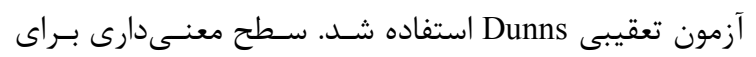
تمام محاسبات ه • P Pر نظر كرفته شد.

\section{يافته ها}

نتايج بر اساس ميانكين \pm انحراف معيار در جدول با ارائه شده

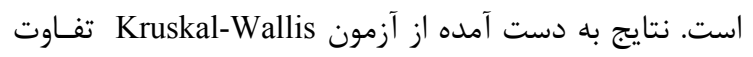




\section{بحث}

در يزوهش حاضر به بررسى اثر نوع تمرين بر بيـان زن B3-ARs

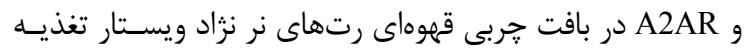

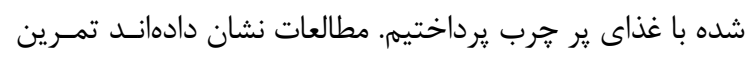

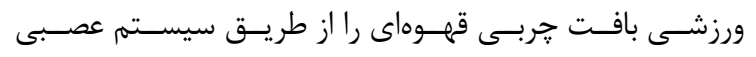
سمياتيك، عضله قلبى و اسكلتى فعال به كار مى گَيرد.

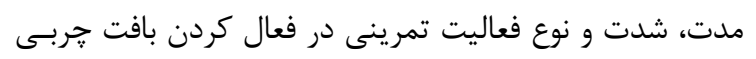

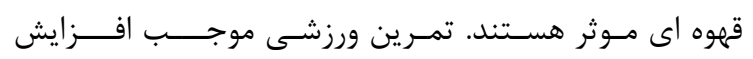

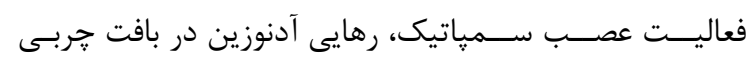

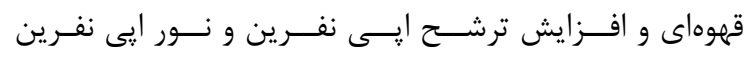

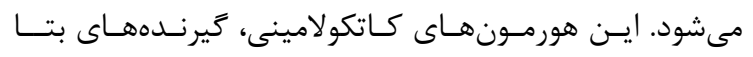

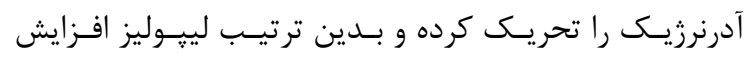

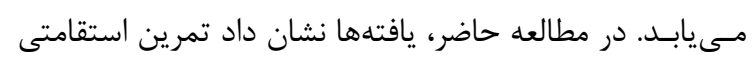

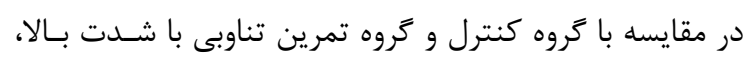

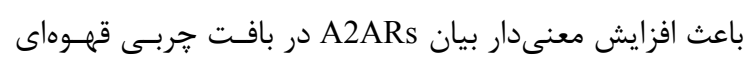

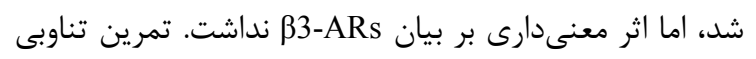

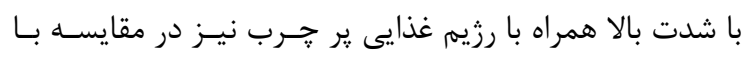

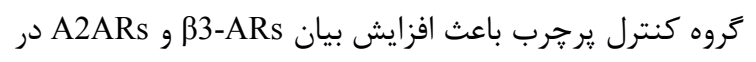

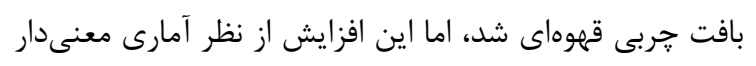

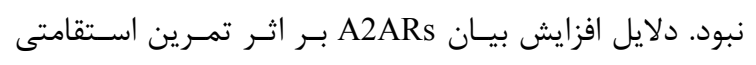

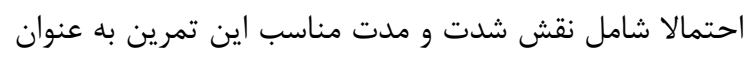

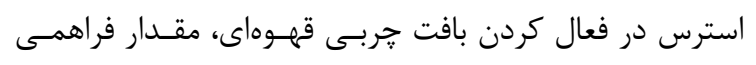

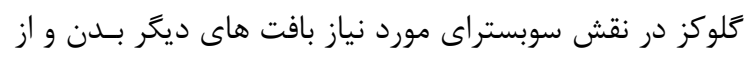

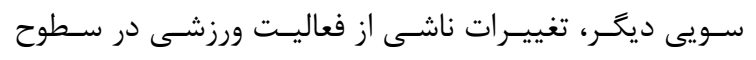

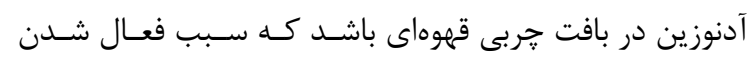

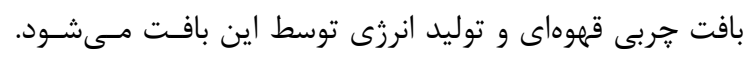

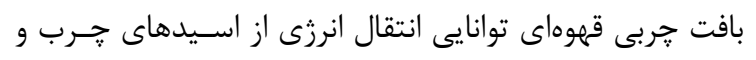

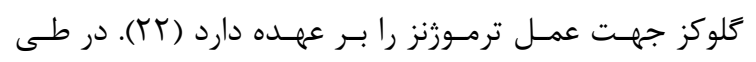

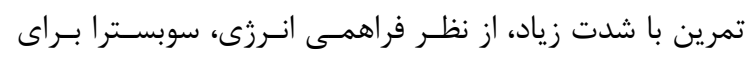

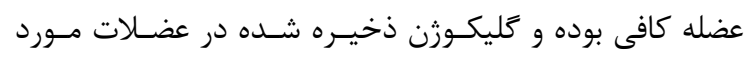

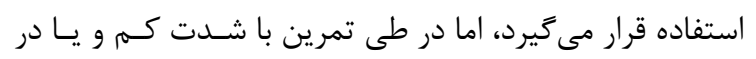

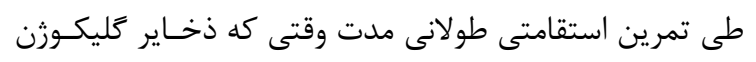

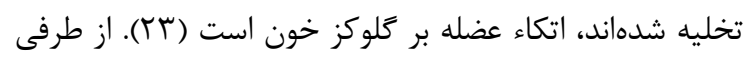

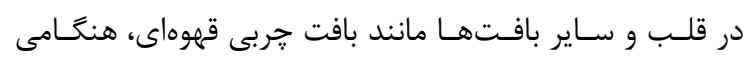

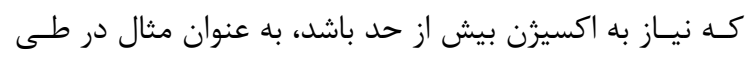

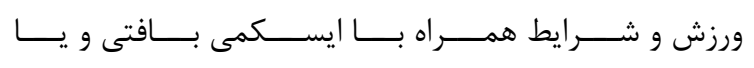

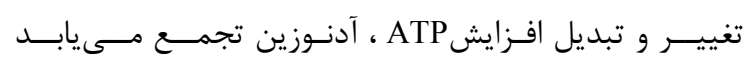
(YY) مىشود، آدنوزين در طى انقباض عضلانى از تجزيه ATP خارج

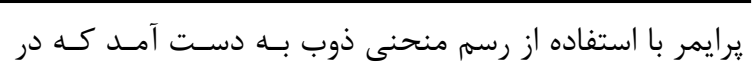
شكل ا اورده شده است.

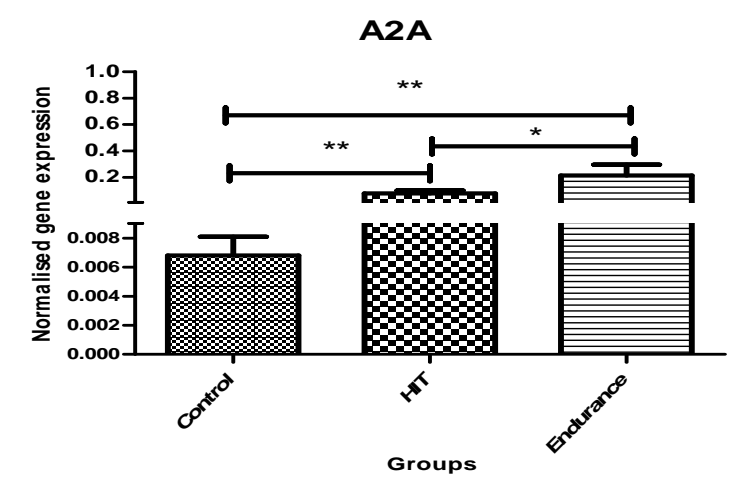

نمودار r. نتايج آزمون Kruskal-Wallis بيان A2ARs در سه گروه

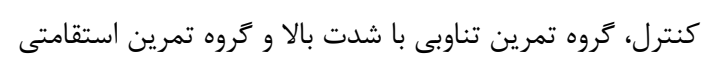

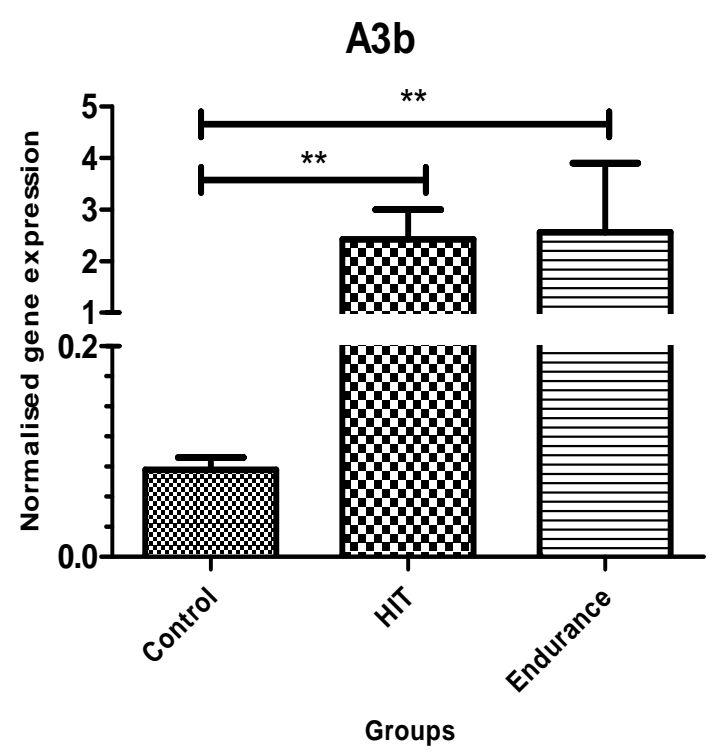

نمودار س. نتايج آزمون Kruskal-Wallis بيان 33-ARS در سه كروه كنترل، گروه تمرين تناوبى با شدت بالا و گروه تمرين استقامتى

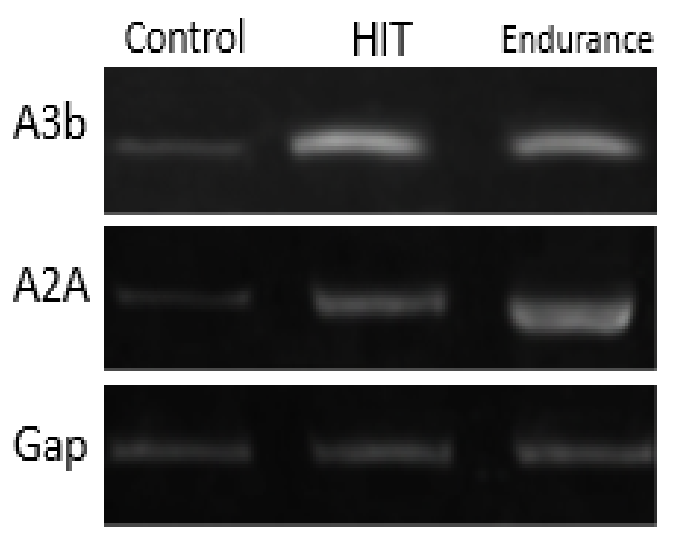
شكل ا. تصوير زل الكتروفورز در گروه هاى مختلف مورد آزمون 
تمرين را موثر دانست كه طبق آنجه در بالا بيان شـد احتمـالا

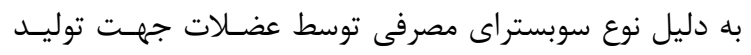

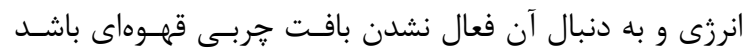

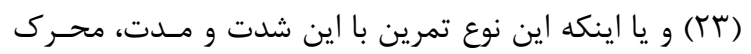

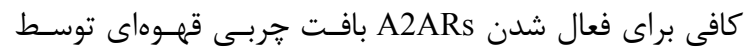

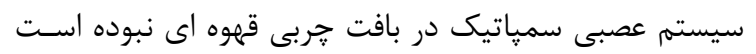

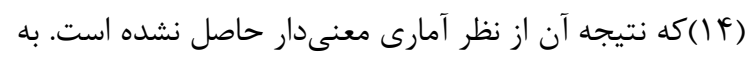

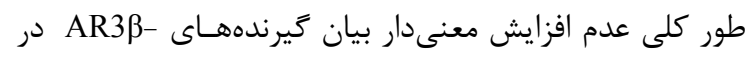

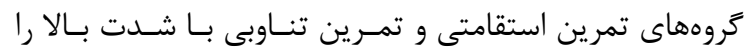

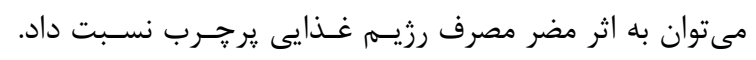

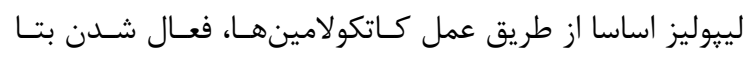

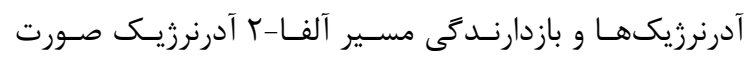

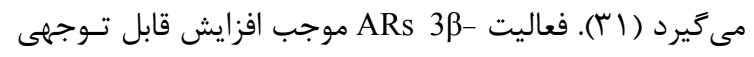

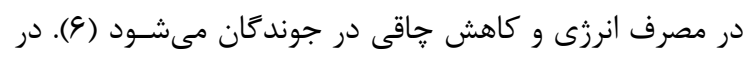

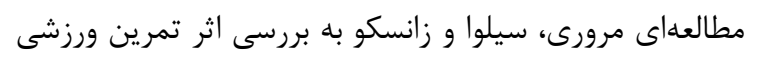

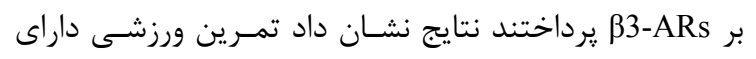

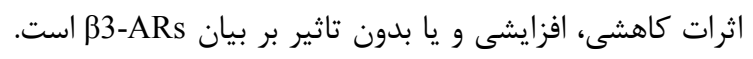

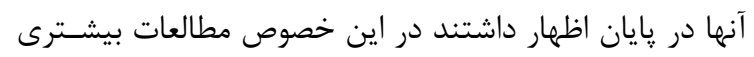

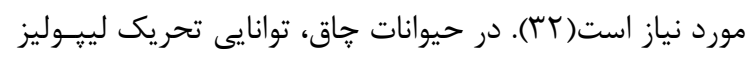

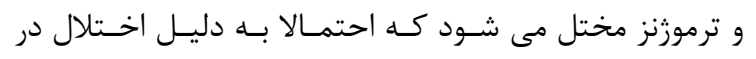

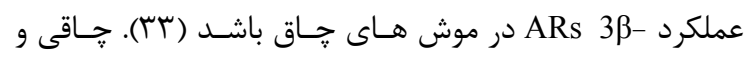

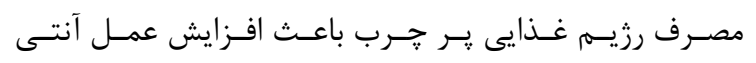

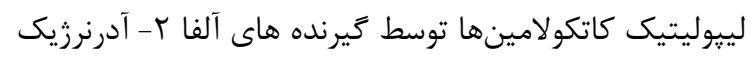
(ARs-2a)

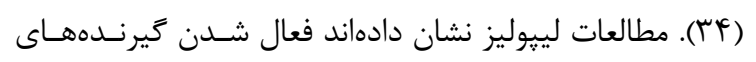

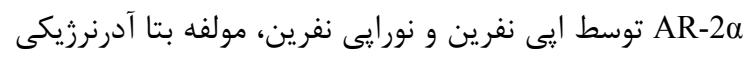

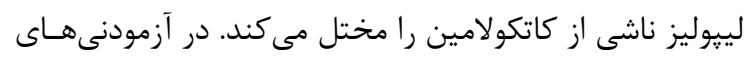

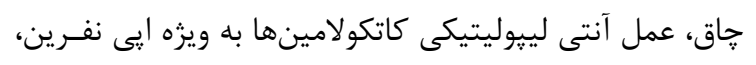

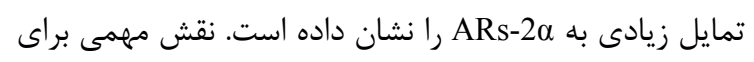

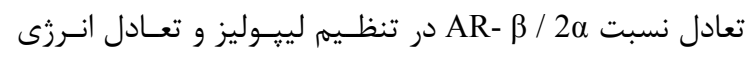

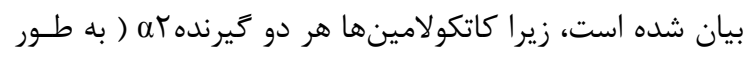

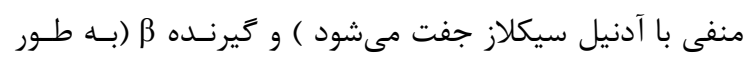

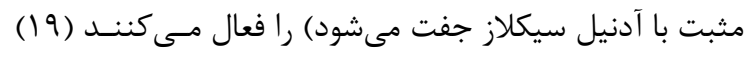

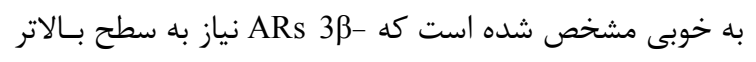

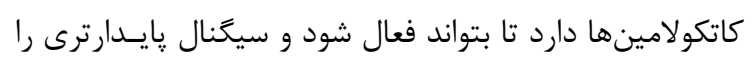

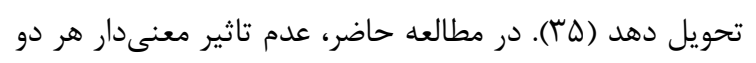

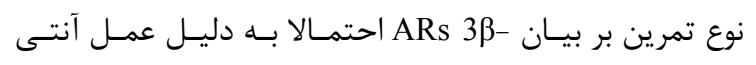

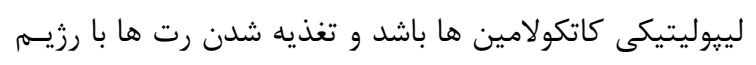

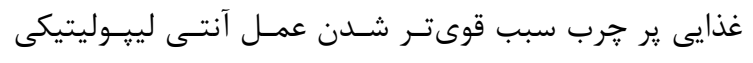

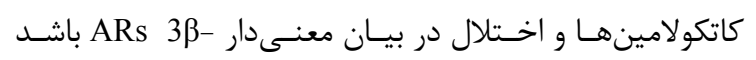

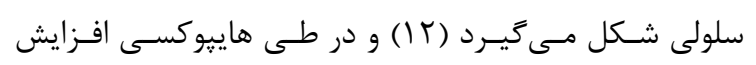

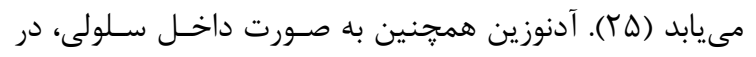

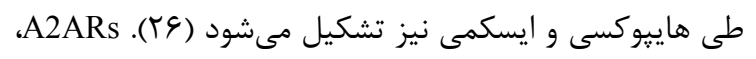

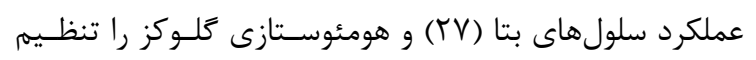

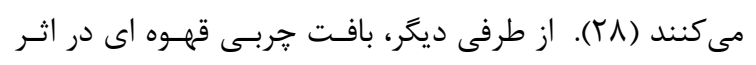

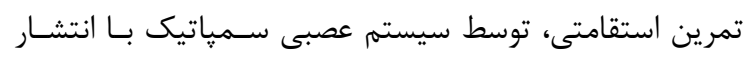

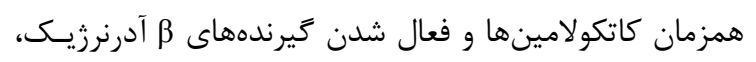

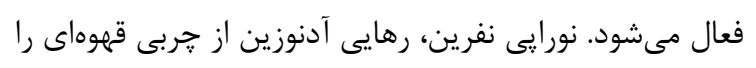

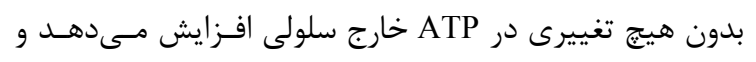

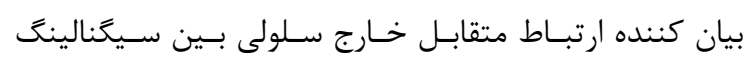

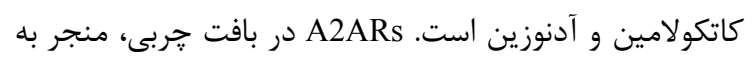
افزايش cAMP و فعال كننده تكثيـر يراكسى زومسى (

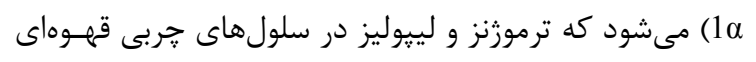

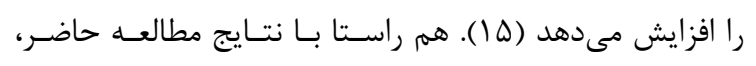

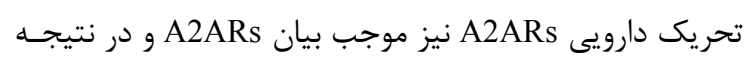

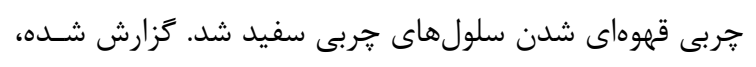

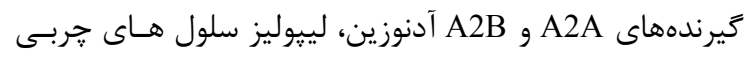

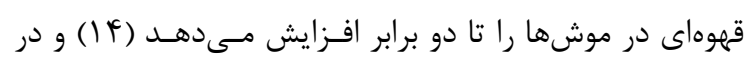

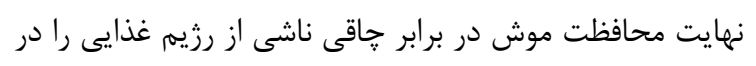

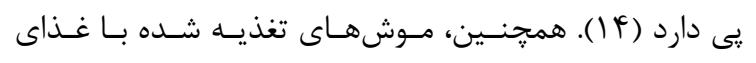

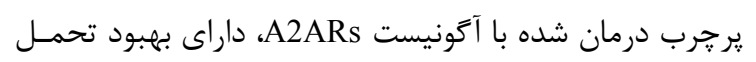

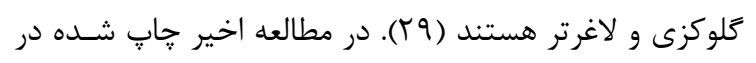

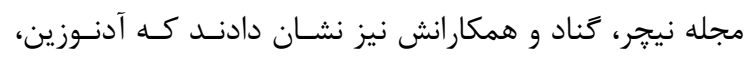

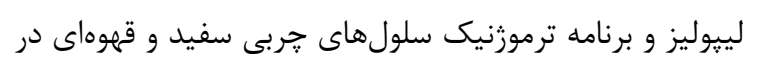

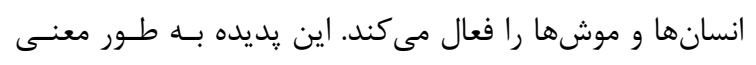

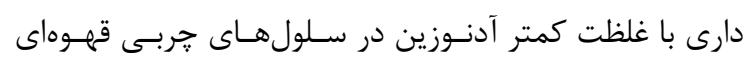

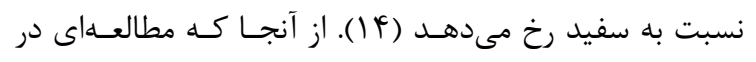

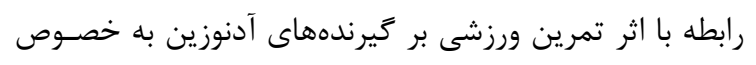

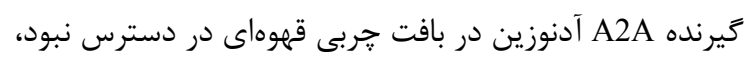
به بررسى نتايج اثرات تمرين شنا با شدرت مترني

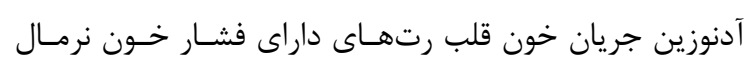

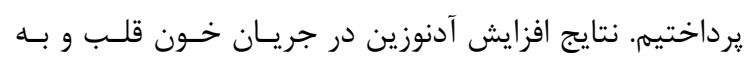

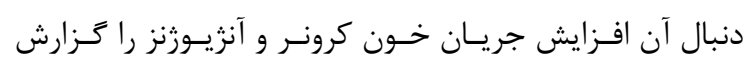

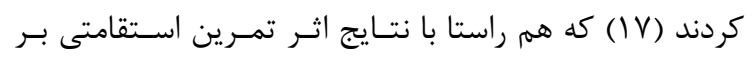

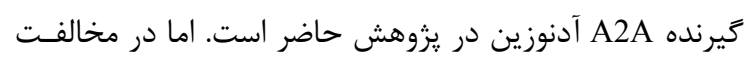

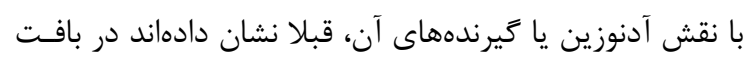

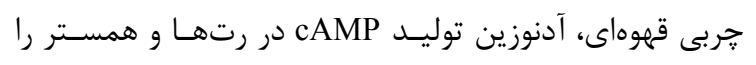

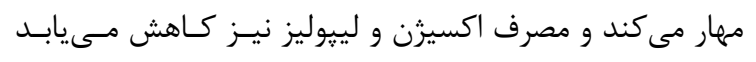

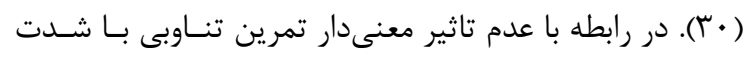

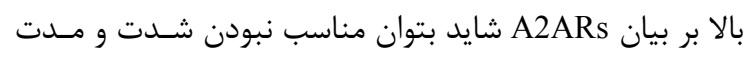


شدت بـالا بـر بيـان زن-ARs و $3 \beta$ و A2ARs در بافـت جربسى

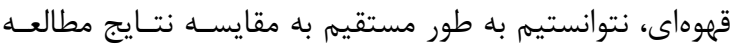

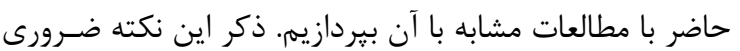
است كه علاوه بر اثر فعاليت ورزشى بر بافت جربسى قهـوهاى،

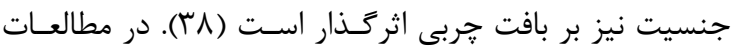

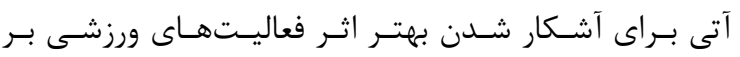

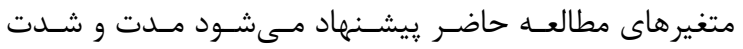
تمرين، جنس آزمودنىها و عوامل هورمونى مانند كـاتكولامين

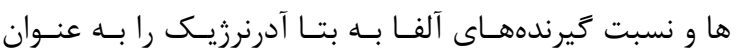
فاكتورهاى مهلم مورد توجه قـرار داد. در نهايـت، بــا توجـهـ بــه

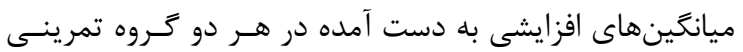

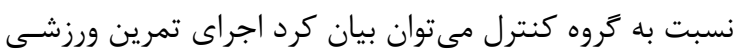
در مقايسه با بى تحركى براى بهبـود بيـان زنهـاى B3-ARs و

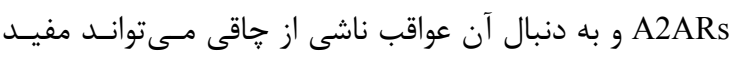

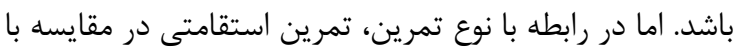
تمرين تناوبى با شدت بالا اثرات افزايشى معنىىدارى بـر بيـان

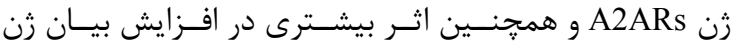
گيرنده ز3-AR داشته است كه نشان دهنده مناسب و مـوثرتر بودن اين نـوع تمـرين در جلـوگيرى از جـاقى ناشـى از رزيـهم غذايى نامناسب يا برجرب و وكاهش وزن است

\section{تشكر و قدردانى}

بدين وسيله از زحمات كاركنان مركز تحقيقات شهيد ميرغنى

$$
\text { تشكر و قدردانى مىشود. }
$$

(9 (1). در مخالفت با نتايج مطالعه حاضر، اوگاساوارا و همكاران به بررسى اثر تمرين استقامتى بر رسـيتورهاى بتـا آدرنرزيـــ

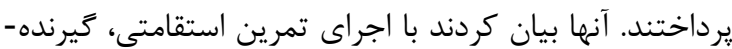

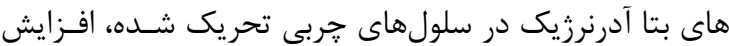
PKA درون سلولى و متعاقبا فعاليـت cAMP يافته و به توليد

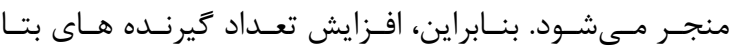

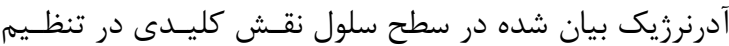

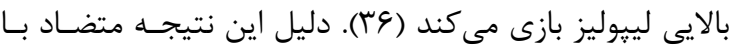

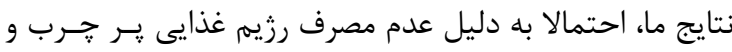
اثر لييوليتيكى كاتكولامينها بر زيرندههاى بتا آدرنرزيـك، بـهـ خصوص -ARs 33 باشد. از سويى ديخر شدت و مـدت تمـرين

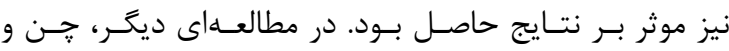

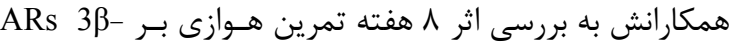

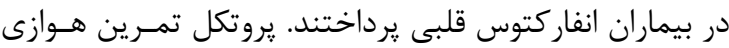

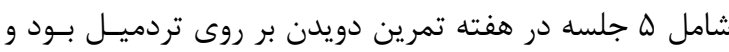

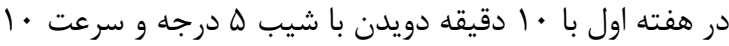

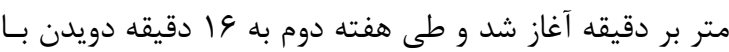

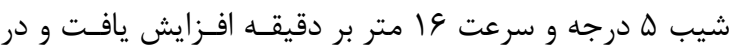

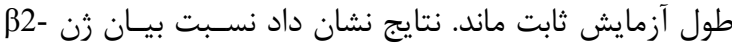
ARS/ק1-ARS نرمال بود اما در گروه تمرين هوازى افزايش معنــى دارى يافتــه

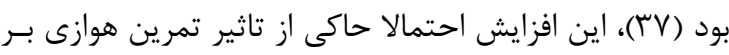
بيان زن -ARs $3 \beta$ و عدم مصرف رزيم غذايى گير هــرب اسـت.

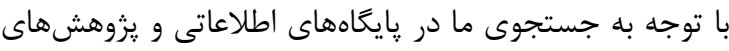

محدود مشابه درباره تاثير تمرين استقامتى و تمرين تناوبى بـا بـا

\section{REFERENCES}

1. Bayati M. Physical inactivity and sedentary lifestyle. IJEM 2012;13:537-9.

2. Malnick SD, Knobler H. The medical complications of obesity. QJM 2006;99:565-79.

3. Lowell BB, Flier JS. Brown adipose tissue, $\beta 3$-adrenergic receptors, and obesity. Annu Rev Med 1997;48:307-16.

4. Lowell BB, Spiegelman BM. Towards a molecular understanding of adaptive thermogenesis. Nature 2000;404:65260 .

5. Kajimura S, Saito M. A new era in brown adipose tissue biology: molecular control of brown fat development and energy homeostasis. Annu Rev Physiol 2014;76:225-49.

6. Thuzar M, Ho KK. Mechanisms in endocrinology: Brown adipose tissue in humans: regulation and metabolic significance. Eur J Endocrinol 2016;175:R11-25.

7. Chaves VE, Frasson D, Kawashita NH. Several agents and pathways regulate lipolysis in adipocytes. Biochimie 2011;93:1631-40.

8. Brasaemle DL. Thematic review series: adipocyte biology. The perilipin family of structural lipid droplet proteins: stabilization of lipid droplets and control of lipolysis. J Lipid Res 2007;48:2547-59.

9. Tataranni PA, Young JB, Bogardus C, Ravussin E. A low sympathoadrenal activity is associated with body weight gain and development of central adiposity in Pima Indian men. Obes Res 1997;5:341-7. 
10. Takahashi A, Tabuchi M, Suzuki W, Iizuka S, Nagata M, Ikeya Y, et al. Insulin resistance and low sympathetic nerve activity in the Tsumura Suzuki obese diabetic mouse: a new model of spontaneous type 2 diabetes mellitus and obesity. Metabolism 2006;55:1664-9.

11. Eisenstein A, Ravid K. G Protein-Coupled Receptors and Adipogenesis: A Focus on Adenosine Receptors. J Cell Physiol 2014;229:414-21.

12. Lynge J, Juel C, Hellsten Y. Extracellular formation and uptake of adenosine during skeletal muscle contraction in the rat: role of adenosine transporters. J Physiol 2001;537:597-605.

13. Sipilä PN, Knuuti J, Boushel R, Kalliokoski KK. Effects of adenosine, exercise, and moderate acute. Am J Physiol Regul Integr Comp Physiol 2012;302:R385-90.

14. Gnad T, Scheibler S, von Kügelgen I, Scheele C, Kilić A, Glöde A, et al. Adenosine activates brown adipose tissue and recruits beige adipocytes via A2A receptors. Nature 2014;516:395-9.

15. Rines AK, Verdeguer F, Puigserver P. Adenosine activates thermogenic adipocytes. Cell Res 2015;25:155.

16. Mubagwa K, Flameng W. Adenosine, adenosine receptors and myocardial protection: an updated overview. Cardiovasc Res 2001;52:25-39.

17. Roque FR, Soci UPR, Angelis KD, Coelho MA, Furstenau CR, Vassallo DV, et al. Moderate exercise training promotes adaptations in coronary blood flow and adenosine production in normotensive rats. Clinics 2011;66:2105-11.

18. Camera DM, Anderson MJ, Hawley JA, Carey AL. Short-term endurance training does not alter the oxidative capacity of human subcutaneous adipose tissue. Eur J Appl Physiol 2010;109:307-16.

19. Richterova B, Stich V, Moro C, Polak J, Klimcakova E, Majercik M, et al. Effect of endurance training on adrenergic control of lipolysis in adipose tissue of obese women. J Clin Endocrinol Metab 2004;89:1325-31.

20. Rocha-Rodrigues S, Rodríguez A, Gouveia AM, Gonçalves IO, Becerril S, Ramírez B, et al. Effects of physical exercise on myokines expression and brown adipose-like phenotype modulation in rats fed a high-fat diet. Life Sci 2016;165:100-8.

21. Carlsson B. Ethical issues in animal experimentation--view of the animal rightist. Acta Physiol Scand Suppl 1986;554:50-68.

22. Golozoubova V, Gullberg H, Matthias A, Cannon B, Vennström Br, Nedergaard J. Depressed thermogenesis but competent brown adipose tissue recruitment in mice devoid of all hormone-binding thyroid hormone receptors. Mol Endocrinol 2004;18:384-401.

23. Rose AJ, Richter EA. Skeletal muscle glucose uptake during exercise: how is it regulated?. Physiol 2005;20:260-70.

24. Koos BJ. Adenosine A(2a) receptors and $\mathrm{O}(2)$ sensing in development. Am J Physiol Regul Integr Comp Physiol 2011;301:R601-22.

25. Leuenberger UA, Gray K, Herr MD. Adenosine contributes to hypoxia-induced forearm vasodilation in humans. J Appl Physiol (1985) 1999;87:2218-24.

26. Heinonen I, Kemppainen J, Kaskinoro K, Peltonen JE, Sipilä HT, Nuutila P, et al. Effects of adenosine, exercise, and moderate acute hypoxia on energy substrate utilization of human skeletal muscle. Am J Physiol Regul Integr Comp Physiol 2011;302:R385-90.

27. Girgis CM, Cheng K, Scott CH, Gunton JE. Novel links between HIFs, type 2 diabetes, and metabolic syndrome. Trends Endocrinol Metab 2012;23:372-80.

28. Haskó G, Pacher P. A2A receptors in inflammation and injury: lessons learned from transgenic animals. J Leukoc Biol 2008;83:447-55.

29. Abbracchio MP, Burnstock G, Verkhratsky A, Zimmermann H. Purinergic signalling in the nervous system: an overview. Trends Neurosci 2009;32:19-29.

30. Schimmel RJ, McCarthy L. Role of adenosine as an endogenous regulator of respiration in hamster brown adipocytes. Am J Physiol 1984;246:C301-7.

31. Pistor KE, Sepa-Kishi DM, Hung S, Ceddia RB. Lipolysis, lipogenesis, and adiposity are reduced while fatty acid oxidation is increased in visceral and subcutaneous adipocytes of endurance-trained rats. Adipocyte 2015;4:22-31.

32.Silva AS, Zanesco A. Physical exercise, $\beta$-adrenergic receptors, and vascular response. J Vasc Bras 2010;9:47-56.

33. Collins S, Daniel KW, Petro AE, Surwit RS. Strain-Specific Response to $\beta$ 3-Adrenergic Receptor Agonist Treatment of Diet-Induced Obesity in Mice. Endocrinology 1997;138:405-13. 
34. Kumar A, Gallagher EJ, Shiloach J, Betenbaugh MJ. The beta-3 adrenergic agonist (CL-316,243) restores the expression of down-regulated fatty acid oxidation genes in type 2 diabetic mice. Nutr Metab 2015;12:8.

35. Lladó I, Rodríguez-Cuenca S, Pujol E, Monjo M, Estrany ME, Roca P, et al. Gender Effects on Adrenergic Receptor Expression and Lipolysis in White Adipose Tissue of Rats. Obes Res 2002;10:296-305.

36. Ogasawara J, Izawa T, Sakurai T, Sakurai T, Shirato K, Ishibashi Y, et al. The molecular mechanism underlying continuous exercise training-induced adaptive changes of lipolysis in white adipose cells. J Obes 2015:10.

37. Chen T, Cai MX, Li YY, He ZX, Shi XC, Song W, et al. Aerobic exercise inhibits sympathetic nerve sprouting and restores $\beta$-adrenergic receptor balance in rats with myocardial infarction. PLoS One 2014;9:e97810.

38. Roca P, Rodriguez AM, Oliver P, Bonet ML, Quevedo S, Picó C, et al. Brown adipose tissue response to cafeteria diet-feeding involves induction of the UCP2 gene and is impaired in female rats as compared to males. Pflugers Arch 1999;438:628-34. 